\title{
Neurologic uses of botulinum neurotoxin type $A$
}

\author{
John P Ney \\ Kevin R Joseph \\ Madigan Army Medical Center, \\ Neurology Service, Tacoma, WA, USA
}

Correspondence: John P Ney

Neurology Service, 9040A Fitzsimmons

Drive, Tacoma, WA 9843I, USA

$\mathrm{Tel}+|206280| 457$

Fax + I 2539680443

Email john.ney@na.amedd.army.mil or

jney_pubs@yahoo.com

\begin{abstract}
This article reviews the current and most neurologic uses of botulinum neurotoxin type A (BoNT-A), beginning with relevant historical data, neurochemical mechanism at the neuromuscular junction. Current commercial preparations of BoNT-A are reviewed, as are immunologic issues relating to secondary failure of BoNT-A therapy. Clinical uses are summarized with an emphasis on controlled clinical trials (as appropriate), including facial movement disorders, focal neck and limb dystonias, spasticity, hypersecretory syndromes, and pain.
\end{abstract}

Keywords: botulinum neurotoxins, BOTOX ${ }^{\circledR}$, Dysport ${ }^{\circledR}$, chemodenervation

Botulinum neurotoxins have evolved in the past fifty years from a reputation for lethality and potential as weaponry in biological warfare to safe in-office treatment for a host of medical conditions ranging from wrinkles to sphincteric dysfunction. The effects of these toxins at the neuromuscular junction lends themselves to neurologic diseases of muscle overactivity, particularly abnormalities of muscle control. Additional studies have pointed to therapeutic efficacy of botulinum toxins in hypersecretory and painful disorders. This review focuses on botulinum neurotoxin type A (BoNT-A) in commonly used therapies for neurological diseases.

\section{History and background}

Botulism was first described in the early 19th century following an outbreak of poisonings from the ingestion of blood sausages. The term "botulism" owes its origins to this association, as botulus is latin for "sausage" (Erbguth 1996). By the end of the 1800s, the organism Clostridium botulinum was isolated after a case of fatal food poisonings, and a neurotoxic mechanism was postulated. Victims were described as suffering from a rapidly progressive paralysis with intact cognition, ultimately causing fatal respiratory insufficiency (van Ermengem 1979). The canning of food for long-term preservation led to a number of botulism outbreaks in the early 20th century in the United States. The industry reacted with better canning techniques (Meyer 1956) and doctors attempted to counter the toxin effects. The development of antisera capable of neutralizing the toxin effect in one outbreak with lack of efficacy in another led to discovery of differing immunologic serotypes (Sakaguchi 1983). Botulinum toxin type A was purified and crystallized in the post-World-War II search for biological weaponry measures and countermeasures by United States Army researchers (Schantz and Johnson 1997).

Botulism remains a deadly illness that can result from ingestion, enteric bacterial overgrowth, or wound infection. Food-borne botulism causes regular outbreaks with symptoms ranging from mild diplopia to muscle weakness and respiratory compromise (Silberstein 2004). Infantile botulism results from ingestion of Clostridium spores, is associated with honey intake, and is a cause of acquired hypotonia (Shapiro et al 1998). Clostridium spores are present in soil, but may also contaminate illicit intravenous 
drugs, with the typical syndrome of descending weakness resulting from intramuscular injections (wound botulism) (Cooper et al 2005).

Despite the dangers of botulism, therapeutic use of BoNT-A was begun in the late 1960s, when an ophthalmologist, Dr. Alan B. Scott, successfully injected rhesus monkey extraocular muscles to correct strabismus. His results were later replicated in humans (Scott et al 1973). Studies showed efficacy in the treatment of muscle control syndromes such as blepharospasm and cervical dystonias. Further purification of BoNT-A led to the US Food and Drug Administration (FDA) approval for treatment of blepharospasm, strabismus, and facial nerve dysfunction in 1989. Commercially available BoNT-A was marketed by Allergan, Inc. (Irvine, CA) as BOTOX ${ }^{\circledR}$, and by Ipsen, Ltd. (Slough, UK) as Dysport ${ }^{\circledR}$. Xeomin ${ }^{\circledR}$, a protein-free BoNT-A manufactured by Merz Pharmaceuticals GmbH (Frankfurt-am-Main, Germany), and Prosigne ${ }^{\circledR}$ (Lanzhou Biologic Products Institute, China), a Chinese formulation of BoNT-A, are approved for usage in Germany $\left(\mathrm{Xeomin}^{\circledR}\right)$ and parts of Asia and South America (Prosigne ${ }^{\circledR}$ ). In 2000, cervical dystonia became an FDA-approved indication for both serotypes $\mathrm{A}$ and $\mathrm{B}$ of botulinum neurotoxin. Current FDA-approved uses of BoNT-A also include the reduction of glabellar lines and the treatment of axillary hyperhidrosis (Cheng et al 2006). Off-label in the United States include the treatment of sialorrhea, muscle control disorders (limb dystonias and spacticity), and painful disorders (low back pain, headache).

\section{Mechanism}

The anaerobic bacillus Clostridium botulinum secretes seven known serotypes of botulinum toxin, typed alphabetically A-G. The toxins are $150 \mathrm{kd}$ single chain polypeptides which undergo protease-mediated nicking to form heavy and light chains (Montecucco et al 1996). Heavy chains irreversibly bind to the SV2 receptor on the presynaptic membrane (Dong et al 2006), allowing for entry of the toxin into the axon terminal (Simpson 1980). Once inside the axon, the light chains act to impede exocytosis of acetylcholine. Specifically, the toxins are zinc-dependent metalloproteases that interfere with portions of the SNARE (soluble N-ethylmaleimide-sensitive factor attachment protein receptor) protein complex (Hay 2001). The SNARE complex allows for fusion of neurotransmitter-containing intra-axonal vesicles with the presynaptic membrane, resulting in extrusion of acetylcholine into the synaptic cleft. Botulinum toxin type $\mathrm{A}$ is responsible for cleavage of the SNARE component SNAP-25 (25 kilodalton synaptosomal- associated protein) molecule (Blasi et al 1993), whereas botulinum toxin type B cleaves SNARE component synaptobrevin (vesicle-associated membrane protein or VAMP). Only types A and B have been utilized for commercial applications.

Botulinum neurotoxins reduce presynaptic outflow of acetylcholine at the neuromuscular junction, with a consequent diminution in muscle contraction. A basal rate of acetylcholine secretion across the synaptic cleft occurs continuously, with each packet of acetylcholine depolarizing the post-synaptic membrane to create miniature end plate potentials (MEPPs). MEPPs summate to maintain the motor end-plate potential (EPP). Botulinum neurotoxins prevent acetyclcholine secretion, reducing the frequency and quantity, but not amplitude of MEPPs. (Maselli et al 1992) BoNT-A effects a reduction in MEPP frequency twice that of BoNT-B. (Simpson 2000) The motor EPP is reduced below the muscle membrane threshold and the ability to generate muscle fiber action potentials and subsequent contraction is diminished. The muscle fibers supplied by the nerve terminal affected by botulinum toxins are effectively denervated (with dose and diffusion-gradient -related reduction in the size of muscle fibers (Borodic et al 1994)), although the gross histologic appearance of the neuromuscular junction remains normal (Duchen and Strich 1968).

Once acetylcholine release is effectively impaired from the axon terminal, or terminal bouton, the process of recovery begins. New nerve sprouts emerge from the nodes of Ranvier in the region preceding the presynaptic membrane. These may begin in as little as one week after botulinum neurotoxin administration in the case of slow-twitch muscle fibers, or up to 6 weeks for fast-twitch muscles (Duchen 1971). Sprouts form new neuromuscular junctions and new endplates with adjacent muscle. Acetylcholine is released from new nerve terminals, and as new endplates mature, functional recovery begins. Muscle fiber atrophy may occur prior to full maturation of the motor end plates. Eventually, the SNARE protein complex is regenerated, acetylcholine release resumes from the original nerve terminal, and axon sprouts retract (de Paiva 1999). The functional paralysis usually lasts for 3-4 months.

\section{Formulations, safety, and adverse effects}

The commercial formulation of BoNT-A as BOTOX ${ }^{\circledR}$ is packaged as a vacuum-dried powder, 100 units per vial. Specific activity of BOTOX ${ }^{\circledR}$ is rated at $20 \mathrm{U} / \mathrm{ng}$. The $150 \mathrm{kDa}$ botulinum neurotoxin molecule is complexed with $600 \mathrm{kDa}$ 
hemagglutinizing and non-hemagglutinizing non-toxic proteins (Dressler and Hallett 2006) for a total concentration of $5 \mathrm{ng}$ per 100 units in its current formulation. $0.5 \mathrm{mg}$ of human albumin is present in each vial as an excipient. Storage at $2{ }^{\circ} \mathrm{C}-8{ }^{\circ} \mathrm{C}$ is recommended. The shelf life is 2 years. To administer the medication, the vial is reconstituted with $1-4 \mathrm{ml}$ of normal saline $(0.9 \% \mathrm{NaCl})$, and given intramuscularly within 4 hours of reconstitution (BOTOX ${ }^{\circledR}$ package insert 2004). Retail cost is approximately $\$ 600$ US per vial.

Dysport $^{\circledR}$ is distributed in $500 \mathrm{U}$ vials as a freeze-dried powder with $0.125 \mathrm{mg}$ albumin and $2.5 \mathrm{mg}$ lactose as excipients. Specific activity of Dysport ${ }^{\circledR}$ is rated at 40U/ng. Protein content is $12.5 \mathrm{ng} /$ vial. Storage and reconstitution are similar to BOTOX $^{\circledR}\left(\right.$ Dysport $^{\circledR}$ package insert 2005).

$\mathrm{Xeomin}^{\circledR}$ is packaged in $100 \mathrm{U}$ vials as a freeze-dried powder with handling and administration similar to BOTOX ${ }^{\circledR}$ (Jost et al 2007). Prosigne ${ }^{\circledR}$ formulation, handling and administration requirements were not available as of this writing. Table 1 compares the commercial BoNT-As based on available data.

Dosing conversions between various preparations of BoNT-A is not necessarily intuitive. Studies of Xeomin ${ }^{\circledR}$ and Prosigne $^{\circledR}$ use unit dosing comparable (1:1) with BOTOX (Rieder et al 2007; Wohlfarth et al 2007). BOTOX ${ }^{\circledR}$ to Dysport ${ }^{\circledR}$ dosing has been suggested to be anywhere from 1:2 to 1:6 (Rosales et al 2006). Dosing of Dysport ${ }^{\circledR}$ should be based on trials conducted with that formulation of BoNT-A rather than an absolute conversion ratio from BOTOX ${ }^{\circledR}$.

Athough botulinum toxin is one of the most deadly neurotoxins known (Osbourne et al 2007), the therapeutic administration of BoNT-A is quite safe. Studies of intramuscular administration of BoNT-A in laboratory-based non-human primates showed an LD50 of $38 \mathrm{U} / \mathrm{kg}$ in a study of eight rhesus monkeys (Scott and Suzuki 1988), and a minimal lethal dose of $24 \mathrm{U} / \mathrm{kg}$ in adult cynomolgus monkeys (BOTOX ${ }^{\circledR}$ package insert). For a $75 \mathrm{~kg}$ man, this works out to be $1800 \mathrm{U}$. The LD50 in conventional laboratory mouse assay units has not been consistently established (Settler 2002).
Both serious and more benign side effects have been reported with BoNT-A administration. Injections are local, intramuscular, and systemic complications are rare (BOTOX $^{\circledR}$ package insert 2004). More concerning events include ptosis and diplopia for strabismus, and dysphagia from injection for cervical dystonia (reported in up to $24 \%$ of patients in one trial (Commella and Thompsen 2006)). This latter event is most disturbing for relatively high frequency and for increased risk of aspiration pneumonia. Other adverse events include cough, fever, upper respiratory infection, flulike malaise, headache, and very commonly, injection site reactions (erythema, swelling) and bruising. Hypersensitivity reactions such as edema and dyspnea have been noted. Anaphylaxis has been reported in one patient who received BOTOX $^{\circledR}$ mixed with lidocaine. Spontaneous death after botulinum toxin $\mathrm{A}$ administration has been reported, but a causal link has not been established. A meta-analysis of controlled trials for BOTOX ${ }^{\circledR}$ efficacy in a variety of conditions concluded that focal weakness local to the area of injection were the only consistent events not reflected in controls (Naumann and Jankovic 2004). Generally, these events were mild to moderate in severity, temporary, and related to the medication's mechanism of action. Strategies for avoiding focal weakness include minimal dilution of the BoNT-A (eg, 100U/1cc for BOTOX ${ }^{\circledR}$ ), this prevents diffusion of the neurotoxin outside the target location. Division of doses with to multiple sites allows for less neurotoxin in a single depot in muscle, with less focal functional denervation, and a presumed reduction in focal weakness.

\section{Tolerance and immunogenicity}

An antibody-mediated tolerance has been invoked as a rationale for secondary failure of BoNT-A after initial good response to treatment. BoNT-A and the proteins complexed with the neurotoxins provide sites of antigenic stimulation and ultimately antibody formation, as has been demonstrated experimentally with Western Blot (Hanna and Jancovic 2000) or ELISA. The commercially available assessment of antibodies is done using a mouse lethality assay (MLA),

Table I BoNT-A commercial formulations

\begin{tabular}{lllll}
\hline Trade Name & BOTOX $^{\circledR}$ & Dysport $^{\circledR}$ & Xeomin $^{\circledR}$ & Prosigne $^{\circledR}$ \\
\hline Manufacturer & Allergan, Inc. & Ipsen, LTD. & Merz Pharmaceuticals & Lanzhou Biological Products Institute \\
Country of origin & USA & UK & Germany & China \\
Protein amount & $5 \mathrm{ng} / \mathrm{IO0U}$ & $\mathrm{I} 2.5 \mathrm{ng} / 500 \mathrm{U}$ & None & $?$ \\
BOTOX $^{\circledR}$ *Dosing conversion & $\mathrm{I}: \mathrm{I}$ & $\mathrm{I}: 2-\mathrm{I}: 6$ & $\mathrm{I}: \mathrm{I}$ & $\mathrm{I}: \mathrm{I}$ \\
\hline
\end{tabular}

Based on BOTOX Product Insert 2004; Dysport ${ }^{\circledR}$ product insert 2005; Markey 2004; Jost et al 2007; Tang and Wan 2000 *See text 
or the more sensitive mouse hemidiaphragmatic paralysis model (also known as a mouse protection assay or MPA) (Critchfield 2002). In the MLA, the patient's serum is incubated with a lethal dose of botulinum toxin, then injected into the peritoneal cavities of mice. Laboratory mouse death ensues unless presumed blocking antibodies prevent botulinum neurotoxin function. The MPA uses the same method of serum incubation with botulinum toxin, which is injected in a bath of excised mouse phrenic nerve and hemidiaphragm where amplitude of contraction to electrical stimulation is measured. Failure to produce a $50 \%$ or greater decrement in contraction amplitude is evidence of antibodies to the neurotoxin (Dressler et al 2000).

Antibodies to BoNT-A have been noted in 36\%-60\% of patients with secondary failure of BOTOX ${ }^{\circledR}$ for cervical dystonia (Anderson et al 1992; Jancovic and Schwartz 1995), and in up to $100 \%$ for focal dystonias (Jancovic and Schwartz 1995). These figures are from relatively small series of patients. Subsequent analysis suggested that short intervals between repeated injections and dosage of BOTOX ${ }^{\circledR}$ correlated with antibody development (Dressler and Dimberg 2000). All of these studies were of the BOTOX ${ }^{\circledR}$ formulation prior to 1998.

In 1998, the amount of neurotoxin complex protein in BOTOX $^{\circledR}$ was reduced from $25 \mathrm{ng} / 100 \mathrm{U}$ to $5 \mathrm{ng} / 100 \mathrm{U}$, with a presumed reduction in antigenic potential. Jankovic et al (2003), prospectively tested 119 patients with minimal or no response to the current formulation of BoNT-A treatment for cervical dystonia on two consecutive visits for antibodies using the mouse lethality assay. None of the patients had antibodies noted by a positive MLA. In contrast, 4 of 42 patients treated with the original (FDA-approved 1989-98) formulation of botulinum toxin meeting the same criteria for treatment failure had antibodies present. Although the risk of antibody formation does appear to be significantly decreased with the present formulation of BOTOX ${ }^{\circledR}$, several cases of antibody-associated treatment failure have been reported (Dressler 2004; Dressler and Saberi 2007).

\section{Botulinum toxin $\mathrm{A}$ in clinical neurology}

BoNT-A, by acting at the neuromuscular junction to reversibly alter muscle tone and selectively functionally denervate muscle, is used extensively in disorders of muscle overactivity, such as facial movement disorders, limb and neck dystonias, and spasticity. Botulinum neurotoxins are also effective at inhibiting acetylcholine release at sites other than neuromuscular junction (Dressler 2005), leading to effective treatments for hypersecretory syndromes, especially sialorrhea and hyperhidrosis. Lastly, painful syndromes such as headache and low back pain have been treated with some success by BoNT-A injections.

\section{Facial movement disorders}

With early research for botulinum toxin focusing on selective denervation for dysconjugate gaze, overactivity of muscles involving eye and mouth closure were targeted next. Blepahrospasm is a focal dystonia of eyelid closure, which can be quite disabling and, in more extreme cases, render the sufferer functionally blind (Ben Simon and McCann 2005). Patients may have a noticeable increased frequency in blink rate, endure spasms of eyelid closure, or have continuous lid closure with significantly impaired voluntary eyelid opening. Oromandibular dystonias involve the muscles of mastication, particularly masseter, temporalis, and pterygoid muscles, and can result in disabling jaw deviation, jaw clenching or protrusion (Bhidayasiri et al 2006). Tongue and pharyngeal muscles may also be involved, and the affected patient may be unable to speak, chew, or swallow effectively. Meige syndrome describes oromandbular dystonia and blepharospasm in combination (Tolosa 1988). Hemifacial spasms are non-dystonic paroxysms of muscle twitching on one side of the face, often due to vascular compression of the 7 th cranial nerve, variably including upper and lower facial nerve-innervated musculature (Tan 2002).

\section{Blepharospasm}

Effective management of blepharospasm with BoNT-A was established largely via small, uncontrolled, open-label trials (Scott et al 1985; Kennedy et al 1989; Borodic and Cozzolino) prior to United States FDA approval of BOTOX ${ }^{\circledR}$. A recent Cochrane Review and metanalysis of BoNT-A and blepahrospasm (Costa et al 2005) found a paucity of blinded, controlled trials consisting of small numbers only. Review of pooled case-controlled data of over 2500 patients demonstrated a $90 \%$ efficacy rate of BoNT-A injections in blepharospasm (Jost and Kohl 2001). Most published clinical research was conducted with BOTOX $^{\circledR}$, but Dysport ${ }^{\circledR}$ has also proven efficacy in placebo-controlled and head-to-head settings comparable to BOTOX ${ }^{\circledR}$ (Truong 2005). Likewise, a trial of equal units of $\mathrm{Xeomin}^{\circledR}$ (NT 201) vs BOTOX ${ }^{\circledR}$ (Wohlfarth et al 2007) yielded comparable success for blepharospasm management.

The large volume and duration of practitioner experience has distilled into recommended injection strategies for blepharospasm. Up to $20 \mathrm{U}$ per eye of BOTOX $^{\circledR}$ are injected 
into the orbicularis oculi at 2.5-5.0U per site through a 27-30 gauge needle. Two injections are made at the upper lid near the canthus medially and laterally to avoid the bulk of the levator palpebrae muscle and consequent ptosis (Bhidayasiri et al 2006). Two lower lid injections are conducted one in the middle portion, and one at the lower lateral canthus. Avoidance of the medial canthus spares the nasolacrimal apparatus (Bhidayasiri et al 2006). Dysport ${ }^{\circledR}$ dosing ranges from 40-120U per eye in clinical trials (Truong 2005). Adverse effects of periocular BoNT-A injection include ptosis, dry eyes, and diplopia. Avoidance of the medial aspect of the lower lid, and injection into the pre-tarsal region rather than the preseptal orbicularis oculi may increase efficacy and reduce complications (Cakmur et al 2002).

\section{Oromandibular dystonia}

Oromandibular dystonias have responded poorly to systemic medications (clonazepam, anticholinergics, and antispasmodics) (Greene et al 1988), but mostly small openlabel trials of BoNT-A indicate significant improvement with neurotoxin injection. Most studies have been done using BOTOX ${ }^{\circledR}$, but similar effects have been obtained in small series with Dysport ${ }^{\circledR}$ (Van der Bergh et al 1995). In a prospective uncontrolled study of 162 patients followed an average of 4.4 years, Tan and Jankovic (Tan and Jancovic 1999) noted a mean duration of effect of 16.4 weeks and global improvement effect rated as a 3.1/4. Greatest improvement was seen in patients with primarily jaw-closure dystonias. Jaw opening dystonias proved more difficult to treat and had a $40 \%$ incidence of dysarthria and dysphagia (relative to only 19\% with treated jaw closure dystonias.)

Injection strategies for BoNT-A in oromandibular dystonias should be individualized to target the specific anatomy of the dystonic movements. Jaw closure dystonia injections should include the masseters, and temporalis muscles, at starting doses of $40-50 \mathrm{U}^{\text {BOTOX }}{ }^{\circledR}$ or $100 \mathrm{U}^{\text {Dysport }}{ }^{\circledR}$ each; medial pterygoids may also be targeted with $20 \mathrm{U}$ BOTOX ${ }^{\circledR}$ or $30 \mathrm{U}$ Dysport $^{\circledR}$ (Bhidayasiri et al 2006). Jaw opening dystonias should focus primarily on the lateral pterygoids, with starting doses of $20 \mathrm{U}^{\mathrm{BOTOX}}{ }^{\circledR}$ (Blitzer et al 1989) or 60U Dysport $^{\circledR}$ (Bhidayasiri et al 2006). The submentalis complex (mylohyoid, geniohyoid, and anterior digastricus) has been targeted as well, with a recommended starting dose of $20 \mathrm{U}$ BOTOX $^{\circledR}$ or 90 U Dysport $^{\circledR}$ (Bhidayasiri et al 2006). An awareness of the anatomical relationships of these muscles is crucial to avoid nearby secretory and vascular structures. The use of electromyography has been suggested for muscles that are not surface-palpable, but has not been validated.

\section{Hemifacial spasm}

Hemifacial spasm (HFS) has been treated with oral anticholinergic, antispasmodic, and anticonvulsive medications (Kemp and Reich 2004) with small degrees of success. Surgical microvascular decompression has been reported to offer long-term relief in up to $95 \%$ of treated patients (Chung et al 2001), but there may be significant morbidity and mortality from invasive intracranial procedures. BoNT-A offers the hope of symptom reduction or relief without the adverse effects of surgery. Although BoNT-A is routinely used as a treatment for HFS, a thorough scientific validation of efficacy is lacking. A meta-analysis involving BoNT-A (Costa et al 2005) revealed only a single well-designed, prospective, blinded, placebo-controlled trial of 11 patients (treated with BOTOX ${ }^{\circledR}$ ) (Yoshimura et al 1992), in addition to many larger open-label trials, concluding that the medication is safe in HFS and supporting the conclusions of the uncontrolled studies that efficacy ranges from $76 \%-100 \%$. Peak effect was reported at 2 weeks and effect duration was nearly 3 months (Yoshimura et al 1992). Other BoNT-A preparations, Dysport ${ }^{\circledR}$ and Prosigne ${ }^{\circledR}$, were evaluated to have similar success rates as BOTOX $^{\circledR}$ in small randomized, uncontrolled trials but with increased side effects noted (Sampaio et al 1997; Rieder et al 2007).

Therapeutic administration of BoNT-A for HFS is similar to strategies described for blepharospasm, with the addition of targeting very small doses to lower facial muscles as well. In addition to the 4 orbicularis oculi injections suggested for blepharospasm treatment, zygomaticus major, buccinator, and depressor anularis oris have been targeted by some authors, at $1-2 \mathrm{U} \mathrm{BOTOX}{ }^{\circledR}$ or 3-6U Dysport ${ }^{\circledR}$ per muscle (Frei et al 2006). Adverse effects include dry eyes, ptosis, and facial or mouth drooping. Other experts suggest staging upper facial (periorbital) injections first, with lower facial injections only on 2-week follow-up after careful discussion with the patient about likelihood of significant lower facial drooping, including lip biting and asymmetric smile (Mauriello 2002). Precautions for injection include those recommended for BoNT-A injections for blepharospasm, but also to take care to avoid injections into elevators or the lips or mouth such as levator labii superioris, levator angularis oris, and orbicularis oris (Comella and Pullman 2004).

\section{Focal neck and limb dystonias}

Botulinum neurotoxins have been applied with particular success to the treatment of focal neck and appendicular dystonias (Ward et al 2006). Cervical dystonias are involuntary movements or postures of the head, neck, and shoulders. There 
may be head rotation (torticollis), neck flexion (anterocollis) or extension (retrocollis), or lateral deviation (laterocollis). Movements may be spasmodic, rhythmic (tremoring), or fixed. Pain accompanies cervical dystonia in the majority of patients (Lew 2002). Focal dystonias can produce undesirable torsional, flexion or extension movements of the limbs or digits, limiting manual dexterity in the upper extremities, and impairing walking in the lowers (Tarsy and Simon 2006). The most reported, and often most disabling, are the occupational dystonias, particularly writer's cramp and musicians' dystonia. Unwanted hand postures occur in relation to particular tasks, often writing or playing musical instruments (Karp 2004).

\section{Cervical dystonia}

Treatment of cervical dystonia (CD) has been the most studied of all the potential applications of BoNT-A. Early studies showed safety and efficacy in small cohorts (Tsui et al 1985; Tsui et al 1986) with a minority of patients reporting transient neck weakness or dysphagia. A meta-analysis of cervical dystonia treatment trials evaluating BoNT-A from 1986-2002 (Costa et al 2005) revealed 13 controlled studies, eight done using BOTOX ${ }^{\circledR}$, and five with Dysport ${ }^{\circledR}$. Pre-and post-treatment ratings were performed with one of three validated scales: the Toronto Western Spasmodic Torticollis Scale (TWSTRS) (Consky and Lang 1994), the Tsui scale (Tsui et al 1996), and the Cervical Dystonia Severity Scale (CDSS) (Brashear et al 1998). TWSTRS is rated in increasing severity from $0-87$, summed from three subsets for pain (0-20), disability (0-23), and severity (0-25). The Tsui scale measures severity based on presence of head tremor, degree of postural impairment, and spasmodic or continuous quality of the dystonia from 0 (no impaiment) to 25 (severe impairment). The CDSS charts the progression of dystonia in three planes based on angle of deviation from the normal. Studies variably utilized electromyographic (EMG) guidance to help target muscles. A variety of dosing schemes and injection strategies were used.

The metanalysis (Costa et al 2005) pooled data from the relevant trials to find a mean two to three point improvement on the Tsui scale at peak effect, with odds ratio (OR) vs placebo at $95 \%$ confidence interval favoring BoNT-A of 8.16 for a one point improvement of Tsui scale, OR 4.25 for a three point improvement of Tsui scale, and OR 5.47 for any improvement on either the Tsui scale or TWSTRS. Adverse events were reported as mild to moderate, transient or intermittent, with an overall OR of 2.1 vs placebo. The highest likelihood events were again neck weakness
(OR 4.9) and dysphagia (OR 3.9). Subgroup analysis of BOTOX $^{\circledR}$ vs placebo and Dysport ${ }^{\circledR}$ vs placebo showed no statistically significant differences between the two BoNT-A formulations in efficacy or side effects. Trends for dosing were analyzed, and trials involving larger doses of either formulation (BOTOX ${ }^{\circledR}:>200 \mathrm{U}$, Dysport $^{\circledR}>960 \mathrm{U}$ ) suggested increased efficacy but a larger incidence of adverse effects, particularly for Dysport ${ }^{\circledR}$.

Although BoNT-A has statistically proven clinical improvement for treatment of neck dystonia, the disorder is quite heterogeneous in both presentation and therapy solutions and several questions remain unresolved. Like other dystonias, dosing strategies should be modified based on severity and muscle involvement. Experienced clinicians note a mean total of $200 \mathrm{U}$ of BOTOX $^{\circledR}$ or $500 \mathrm{U}^{\text {Dysport }}{ }^{\circledR}$ as effective in cervical dystonias (Jancovic 2004a), but this reflects stable doses rather than starting dosing, and varies significantly per patient. Careful examination and observation of the abnormal movements and postures are essential for developing a successful treatment algorithm (Jancovic 2004b). The WEMOVE ${ }^{\circledR}$ website (http://www.wemove.org or http://www.mdvu.org) is an excellent tool replete with anatomical diagrams and dosing recommendations for CD and other dystonias. Nevertheless, a standardized dosing regimen of 500U Dysport in moderate to severe CD has demonstrated safety and efficacy over a ten week period (Wissel et al 2001).

Primary non-response, duration of effect, and long-term results of BoNT-A treatment of CD have been studied. Although the majority of patients respond to their first dose of BoNT-A, approximately $15 \%$ fail to derive significant improvement of their cervical dystonia. Non-response is reported by patients as the primary reason for discontinuation of BoNT-A treatment (Brashear, Bergan et al 2000). Primary non-responders with longstanding dystonia may have fibrous contractures of neck muscles with rheological changes of soft tissue and muscle, creating fixed postures not amenable to neuromuscular blockade. Anterocollis with inaccessible prevertebral muscle involvement responds poorly to treatment (Comella and Thompson 2006). Inaccurate muscle targeting and insufficient dosing have also been cited as reasons for primary non-response. (Jancovic 2004a) Length of effect has been assessed with retrospective chart review of 60 patients treated for twelve or more months showed a single injection benefit duration of 12.2-24.3 (mean 15.4) weeks (Brashear, Watts et al 2000). Comparison of Dysport ${ }^{\circledR}$ and BOTOX ${ }^{\circledR}$ showed average duration of improvement, as measured by Tsui scores as 83.9 days $\left(\right.$ Dysport $\left.^{\circledR}\right)$ and 80.7 days $\left(\right.$ BOTOX $\left.^{\circledR}\right)$ 
(Odergren et al 1998). Repeated BoNT-A injections for CD indicate continued good response in $63 \%$ of patients treated over ten years (Hsuing et al 2002); secondary non-response was seen in only $7.5 \%$.

EMG guidance of BoNT-A injections for CD is contested. Many of the potentially involved musces of the neck, particularly the scalenes, levator scapulae, and the splenius and semispinalis muscles are quite deep with accuracy impaired using only surface landmarks for localization. A study of needle placement without EMG guidance showed inaccurate placement in the sternocleidomastoid and the levator scapulae in $17 \%$ and $57 \%$ of all attempts, respectively (Speelman and Brans 1995). A randomized study of 52 CD patients receiving BoNT-A injections with and without EMG-guidance showed a statistically greater degree of benefit and number of patients benefiting from EMG-guided injections (Comella et al 1992). Jancovic contends that the degree of benefit is likely minimal relative to a general BoNT-A response rate of $85 \%$, and may not justify the added expense and patient discomfort of EMG (Jancovic 2004b).

\section{Limb dystonias}

Focal dystonias of the upper and lower extremities are particularly well-suited to treatment with localized injections of BoNT-A. Systemic medications carry unwanted central nervous system side effects and are generally ineffective. BoNT-A has the advantage of being a targeted, minimally invasive, reversible therapy, acting at the site of muscle dysfunction with few side effects.

Clinical trials of BoNT-A have focused largely on occupational dystonias, especially writer's cramp (WC). Most studies were open-label, case-controlled, or reports of clinical experience with a number of patients. In one double-blinded, placebo-controlled trial (Tsui et al 1993), 12/20 WC sufferers experienced improved pen control after BoNT-A injections, but only 4/20 noted improved writing ability. A prospective study of 47 patients assessed after BoNT-A injection (Djebbari et al 2004) concluded that patients with forearm pronation and flexion dystonias had the most improvement of their WC. Clinical experience suggests that most patients $(75 \%-80 \%)$ have onset of benefit one week following BoNT-A injection, peaking at two weeks, and lasting 3 months (Das et al 2006). The majority return and continue to have benefit with repeated injections over years (Hsuing et al 2002). Indeed, physiologic studies suggest that successive BoNT-A injections for WC may effect reorganization in the premotor cortex (Byrnes et al 1998).

Leg and foot dystonias are far less common and less well-studied. Case series of primary foot dystonia patients showed improvement to repeated BoNT-A injections in 6/8 (Schneider et al 2006). Four patients with primary foot dystonias received significantly greater benefit from BoNTA injections than oral pharmacotherapies in a retrospective review (Singer and Papapetropoulos 2006).

The administration of BoNT-A therapy for limb dystonias, like other focal dystonias, should tailor localization and dose to the individual movements through careful observation and examination. EMG is an invaluable adjunct for muscle localization, as more than half of non-EMG guided BoNT-A injections for limb dystonias may be inaccurately placed (Molloy et al 2002). EMG recording during the task associated with dystonia may be helpful to pinpoint muscle activation patterns (Karp 2004). Injections for WC are usually focused on finger flexors and extensors in the forearm, but wrist pronators and flexors are often involved (Das et al 2006). Dosing ranges from 10-50U BOTOX ${ }^{\circledR}$ and 30-120U Dysport ${ }^{\circledR}$ (Das et al 2006) per muscle. Hand intrinsic muscles may require smaller doses. Lower limb dystonias often present with foot inversion, toe dorsiflexion, and/or ankle plantar flexion. Injected muscles may include tibialis posterior, extensor hallucis longus, gastrocnemius, and long toe flexors.

\section{Spasticity}

Central nervous system disorders with upper motor neuron dysfunction often produce spasticity, hypertonia of the limb that is distinguished from rigidity by being both velocitydependent (Lance 1980) and dependent on range of motion. The muscles most prominently affected are those innervated by the pyramidal tracts. In the upper extremities, the shoulder adductors, elbow flexors, wrist pronators, finger and thumb flexors are most involved (Mayer et al 1997). In the lower extremities, hip adductors (often resulting in hygiene issues), knee extensors, and ankle plantar flexors and inverters may have increased spastic tone (Pathak et al 2006). The most common causes of spasticity in adults are trauma, stroke, and multiple sclerosis, while in children, cerebral palsy (CP) is the primary culprit (Jancovic 2004a). Treatment is aimed at prevention of contractures and improved functional outcome (Brin et al 1997). Similar to dystonias, oral medications may have some benefit, but produce sedation or other cognitive side effects in patients who may have (Dones et al 2006). Intrathecal baclofen has advantages in reduced dosing and likely fewer cognitive effects, but requires surgery for initial placement and is reserved for those with more generalized severe spasticity (Albright et al 2003). 


\section{Adult spasticity}

BoNT-A has been studied as a spasticity treatment in adults. Most studies assessed pre- and post-treatment muscle tone via Ashworth scores. Many were performed in conjunction with electrical stimulation, and physical or occupational therapies. Upper limb tone has been shown in blinded, placebo-controlled studies to improve with 200-300U BOTOX $^{\circledR}$ (Brashear et al 2002; Simpson et al 1996) and up to $1000 \mathrm{U}^{\text {Dysport }}{ }^{\circledR}$ (Hesse et al 1998); the effect is likely dose-dependent (Childers et al 2004). Lower extremity tone improved in spastic patients after BoNT-A injection, especially hip adductors (Hyman et al 2000) and calf spasticity (Mancini et al 2005). Higher doses $\left(>1000 \mathrm{U}\right.$ Dysport $^{\circledR}$ or $>500 \mathrm{U} \mathrm{BOTOX}^{\circledR}$ ) had significantly increased likelihood of adverse events. Functional improvement in spastic, paretic limbs evaluating dexterity and gait after BoNT-A treatment has been limited, at best (Sheehan 2001). The clinicianinjector is directed to the Neurotoxin Institute website (www. neurotoxininstitute.org) which is an excellent clinical tool with dosing schemes, muscle localization charts, and education materials for limb spasticity.

\section{Pediatric spasticity}

BoNT-A as a treatment for the spasticity associated with cerebral palsy has also been studied. Rigorous reviews identified 2 randomized, blinded, placebo-controlled trials for upper limb spasticity (Wasiak et al 2004) and 3 trials for lower limb spasticity (Ade-Hall et al 2001). One upper limb trial (Corry et al 1997) showed statistically significant improvement at two weeks and three months in active range of motion and Ashworth score in a cohort of 14 hemiplegic CP children randomized to normal saline or BoNT-A (BOTOX ${ }^{\circledR}$ at 4-7U/kg or Dysport ${ }^{\circledR}$ at $8-9 \mathrm{U} / \mathrm{kg}$ ). Twenty-nine children with hemiplegic $\mathrm{CP}$ randomized to occupational therapy with or without BOTOX $^{\circledR}$ (total dose 2-6U/kg) (Fehlings et al 2000), trended toward favoring BoNT-A treatment, but did not show significance in relevant outcome measures. No statistically significant difference in outcomes was found in a study of twelve $\mathrm{CP}$ children randomized to calf injections of BOTOX $^{\circledR}(3-8 \mathrm{U} / \mathrm{kg})$ in follow-up (Koman et al 1994). Two trials of casting vs calf injection with BoNT-A (Corry et al 1998; Flett et al 1999) in twenty ambulant CP children each showed largely non-significant trends favoring BoNT-A. All of the above trials suffered from small numbers, and nonstandardized outcome measures, decreasing the likelihood of significance. A larger and more recent trial of 125 children randomized to three doses of Dysport ${ }^{\circledR}(10,20,30 \mathrm{U} / \mathrm{kg})$ and placebo injections to the calves showed significant improvement in gastrocnemius shortening at 4 and 16 weeks (Baker et al 2002). Several very recent trials have focused on the combination of BoNT-A with concurrent occupational therapy (OT). In one study, eighty children with $\mathrm{CP}$ involving the upper limb were randomized to single dose BoNT-A and placebo, with further randomization for 12 weeks of OT in each group. While the functional outcomes were achieved more quickly in the BoNT-A treated groups, there was no difference in final outcome among groups (Wallen et al 2007). In another study, children with hemiplegic CP received 4 sessions of OT and were randomized to receive upper limb BoNT-A. Outcome measures were assessed and grouped based on activity participation, body structure, and self-perception. All three grouped measures improved significantly in the BoNT-A treated group over controls (Russo et al 2007). Despite the preponderance of results failing to show treatment effect, open label trials suggest (Yang et al 2003) and many clinicians feel (Verotti et al 2006) that BoNT-A is a useful adjunct to conventional measures for treatment of $\mathrm{CP}$ and helps to reduce the need for surgical interventions such as heel-cord lengthening.

\section{Hypersecretory syndromes}

Sialorrhea and hyperhidrosis are socially and physically awkward conditions involving secretion of fluids mediated by cholinergic synapses. Primary sialorrhea may result from overproduction of saliva, but more often drooling is the sequelae of neurologic disorders with poor oral or swallowing control (Potulsha and Friedman 2005), such as parkinsonism (Lagalla et al 2006), stroke, or cerebral palsy (Lal and Hotaling 2006). The condition may lead to increased perioral skin irritation, infections, unpleasant odors, social embarrassment and withdrawal. Hyperhidrosis is excessive sweating, often in the palms and soles of the feet, but also in the axillary region and the face. Complications include skin breakdown and dehydration, with possible secondary infections, in addition to social and psychological difficulties. Available treatments for both conditions include oral anticholinergic medications, often with associated unwanted CNS side effects, and surgeries for gland or ductal resection or rerouting (Hockstein et al 2004), or surgical denervation.

\section{Sialorrhea}

Parasympathetic cholinergic nerve terminals at the neurosecretory junction are dependent on the SNARE complex for exocytosis of acetylcholine, which is vulnerable to the action of botulinum toxins (Dolly and Aoki 2006). Injection of BoNT-A into parotid and/or submandibular glands 
has been studied in controlled and open-labeled settings for management of sialorrhea. Controlled studies of adults with Parkinson's disease (Mancini et al 2003) or other neurologic disorders (Lipp et al 2003) found that the drooling was significantly reduced at follow-up of 1 week to 3 months with clinical measures (number of dental rolls, drooling severity and frequency scores). No adverse effects were reported. A study of 45 children with CP comparing BOTOX ${ }^{\circledR}$ at 15-25U/gland with scopolamine (Jongerius et al 2004) showed similar efficacy among the two groups with fewer side effects from BOTOX ${ }^{\circledR}$. Consensus for optimal dosing remains elusive, with wide ranges for both parotid (5-75U BOTOX ${ }^{\circledR}, 10-145$ U Dysport $\left.^{\circledR}\right)$ and submandibular (5-30U BOTOX ${ }^{\circledR}, 70-80$ U Dysport $^{\circledR}$ ) injection (Tan 2006). Although some studies were done using ultrasound-guided techniques, ultrasound guidance may not be necessary for the large and superficial parotids, and may contribute extra cost to an already expensive procedure (Benson and Daugherty 2007).

\section{Hyperhidrosis}

Sympathetic cholinergic nerve terminals in the eccrine and apocrine sweat glands are also amenable to botulinum toxin-mediated blockade (Bhidayasiri and Truong 2005). Axillary sweating (Lowe et al 2007) and palmar hyperhidrosis (Naumann and Jost 2004) treatment with BoNT-A has been studied in randomized clinical trials with objective and subjective measures confirming safety and efficacy. The effect of BoNT-A for palmar or axillary hyperhidrosis lasts for a mean of 7 months (Eisenach et al 2005). A trial comparing 50U BOTOX ${ }^{\circledR}$ and 150U Dysport ${ }^{\circledR}$ (Talarico-Filho et al 2007) found no difference in efficacy or duration of treatment effect for axillary hyperhydrosis. Palmar hyperhidrosis requires higher doses (120U-220U BOTOX ${ }^{\circledR}$ ) due to larger surface area, and a greater number of injections (Naumann and Jost 2004). Adverse effects can include considerable pain necessitating local anesthesia (Benohanian 2007) or nerve block (Campanati et al 2004) and intrinsic hand muscle weakness. Topical use of botulinum toxin has been suggested for hyperhidrosis as well (Lim et al 2006). A pilot study using topical BOTOX ${ }^{\circledR}$ (mixed with a proprietary transport peptide) at $200 \mathrm{U}$ per axilla reduced absolute sweat amount by $40 \%$ relative to placebo at 4 weeks (Glogau 2007). Uncontrolled trials of injected subcutaneous BoNT-A indicate single dose efficacy in Frey's syndrome (gustatory sweating due to aberrant facial nerve reinnervation (Reich and Grill 2005)) for an average of one year with optimum dosing of BOTOX ${ }^{\circledR}$ at $3 \mathrm{U} / \mathrm{cm}^{2}$ affected skin (Nolte et al 2004).

\section{Pain syndromes}

Chronic headache and low back pain are two commonly seen complaints in the neurologist's office. Both involve at least subjective muscular overactivity, particularly the bandlike bitemporal tightening of tension headache, and lumbar muscular spasms.

Treatment of these conditions has been difficult, requiring multiple approaches with both acute and chronic pharmacotherapies and adjunctive measures (Jabbari and Ney 2004; Garza and Swanson 2006).

\section{Botulinum toxin and pain}

BoNT-A as a mediator of pain relief is a subject of considerable speculation, but both central and peripheral nervous system actions have been hypothesized (Lang 2003; Borodic et al 2001). The known effect of BoNT-A at the neuromuscular junction has considerable implications in treating pain of muscular origin. The activation of poorly myelinated group III and unmyelinated group IV afferents (a large fraction of which are nociceptors (Borodic et al 2001)) with overactivation of alpha motor neurons produces abnormal patterns of muscle contraction, resulting in spasm and cramping (Schomburg et al 1999). In diminishing synaptic acetylcholine, the corelease of local factors for nociceptive transmission, such as calcitonin-gene-related protein (CGRP), glutamate, substance $\mathrm{P}$ and bradykinin (Arezzo 2002), is reduced as well.

Altered function of wide dynamic range (WDR) neurons in the central nervous system may also play a role in pain sensitization (Graven-Nielsen and Mense 2001). Chronic pathologic conditions can create a failure of stimulus discrimination in WDR neurons. Non-painful stimuli may be perceived as causing pain. As a wider range of peripheral inputs are perceived as painful, nociception becomes exaggerated (Craig 2003). BoNT-A diminishes non-nociceptive stimuli (such as muscle spindle discharges (Roberts 1986)) to WDR neurons, attenuating pain perception. Additionally, BoNT-A may alter post-ganglionic cholinergic fibers within blood vessels following neuromuscular injection. This may reduce ischemia and prevent sensitization of muscle nociception by local factors. BoNT-A reduction in peripheral glutamatergic pain modulation may also play a role (Cui et al 2004). Neuroplastic mechanisms within the CNS respond to the alteration of stimuli through these mechanisms and the chronic pain state may be ameliorated (Filippi et al 1993; Mannion and Woolf 2000).

\section{Headache}

Anecdotal evidence of botulinum toxin efficacy in headache has been present since early uses in ocular disorders (Dutton 
and Fowler 2007). A number of blinded, placebo-controlled studies have looked at the use of BoNT-A in headache disorders, particularly migraine and chronic tension-type headache (CTTH). Evers and Oelsen (Evers and Oelsen 2006) recently reviewed the results of these studies and concluded that although two of nine studies showed some positive results (Barrientos and Chana 2003; Silberstein et al 2000), that statistical review of the majority of trials failed to show a significant treatment effect. Unfortunately, uniform dosing protocols and injection sites have not been developed, so dismissal of BoNT-A as a prophylactic treatment for headache may be premature (Mauskop 2007). Ultimately, clinical experience suggests that patient selection is important, and a greater focus on the subset characteristics of patients who respond to BoNT-A therapy may provide insight for future trials (Evers 2006).

\section{Low back pain}

Low back pain is exceedingly common and debilitating, and has been demonstrated in limited studies to respond to BoNT-A (Difazio and Jabbari 2002). Foster et al (2001) conducted a randomized, placebo-controlled, doubleblinded study of Botulinum toxin A versus saline injection in 31 patients with unilateral or predominantly unilateral low back pain. Patients were evaluated by quantitative and qualitative pain measures at baseline, three weeks and two months. After injection into paravertebral muscles $73 \%$ of enrollees at 3 weeks and $60 \%$ of enrollees at two months had a significant response. Limitations of this study were the small size of cohort (15 patients received 200 units of $\mathrm{BOTOX}^{\circledR}$ ) and the short duration of observation. The authors reported no significant side effects. Ney and Jabbari demonstrated efficacy in an open-labeled with repeated injections of BoNT-A in patients with initial good-response over a six and fourteen-month time frame (Jabbari et al 2006; Ney et al 2006; Rotenberg et al 2006).

While these studies are encouraging, larger placebocontrolled trials are needed, especially in light of the greater quantity and thus higher cost of neurotoxin that is required for these lower spinal muscles. Clinically, Jabbari and Ney (2004) suggest trigger point-injections of the low back, using 40-50U BOTOX ${ }^{\circledR}$ per injection in four to five sites on each side of the spine. They report a beneficial effect within 7-10 days, lasting 3-4 months.

\section{Other uses of botulinum toxin A}

BoNT-A is becoming the tool of a wide range of medical specialties, often as a part of a multidisciplinary effort involving neurologists and other sub-specialists. Movement and behavioral disorders such as essential tremor (Brin et al 2001), tic disorder (Porta et al 2004), and bruxism (Van Zandijcke and Marchau 1990) have all been the subject of BoNT-A treatment trials. Otolaryngologists and neurologists have long used BoNT-A for the treatment of spasmodic dysphonia (Blitzer 2005), but hypersecretion due to excessive lacrimation (Unal et al 2003; Keegan et al 2002) or rhinitis has also been addressed anecdotally and in treatment trials. Neuro-urologic/procotologic uses in anal fissure (Madalinski and Chodorowski 2006) and bladder emptying disorders (Patel and Chappel 2006) are established. The role of BoNT-A for facial cosmesis is well-known and well-publicized with reduction in glabellar lines and facial rhytides (Flynn 2006) (Table 2).

\section{Future directions}

The uses of BoNT-A discussed in this review is by no means exhaustive, and research into new mechanisms of action as well as new clinical applications is only growing. Success with conditions of muscle overactivity due to central nervous system dysfunction lends BoNT-A to conditions with a possible psychological component such as temporalmandibular joint dysfunction (Schwartz and Freund 2002), vaginismus (Ghazizadeh and Nikzad 2004), and anismus (Ron et al 2001). Experimental reduction in pain-related behavior in rodents pre-treated with BoNT-A has suggested mechanisms of analgesia in inflammatory and neuropathic pain in sensory neurons independent of action at the neuromuscular junction (Cui et al 2004; Aoki 2005; Luvisetto et al 2007), discussed above. BoNT-A for perioperative pain (Davies et al 2003), treatment for amputation stump-related and phantom-limb pain (Kern et al 2003), plantar fasciitis (Babcock et al 2005), carpal tunnel related-pain (Tsai et al 2006), and even refractory restless-legs syndrome (Rotenburg et al 2006) have been reported. Botulinum toxins may have a role in electrodiagnosis, using BoNT-A pretreatment to reduce electromyographic frontotemporal artifact in electroencephalographic localization of aberrant cerebral discharges (Grant and Hermanowicz 2007). Lastly, direct infusion of botulinum toxin A has been shown in vivo to inhibit enzymes responsible for hippocampal cell death following induced seizures in rats (Manno et al 2007). Hence, in addition to its role at the neuromuscular junction and peripheral nerve, BoNT-A may be a neuroprotective agent for the central nervous system. With the all of the current interest and speculation in botulinum neurotoxins, one can only assume that a myriad exciting new therapeutic applications will come to light in the decades. 
Table 2 Web resources for botulinum neurotoxin $\mathrm{A}$

\begin{tabular}{|c|c|c|c|c|c|}
\hline Name & URL & Sponsor/Affiliate & $\begin{array}{l}\text { Dosing } \\
\text { algorithms? }\end{array}$ & $\begin{array}{l}\text { Localization } \\
\text { diagrams? }\end{array}$ & $\begin{array}{l}\text { Patient } \\
\text { education? }\end{array}$ \\
\hline \multirow{3}{*}{$\begin{array}{l}\text { Neurotoxin Institute } \\
\text { WEMOVE }^{\text {TM }}\end{array}$} & http://www.neurotoxininstitute.org & University of South Florida & Yes & Spasticity and Dystonia & Yes \\
\hline & http://wemove.org & & & & \\
\hline & http://www.mdvu.org & WEMOVE $^{\mathrm{TM}}$ & Yes & Spasticity and Dystonia & Yes \\
\hline Xeomin $^{\circledR}$ & http://www.xeomin.com & Merz Pharmaceuticals & No & No & No \\
\hline Dysport $^{\circledR}$ & http://www.dysport.co.nz/index.php & Ipsen, LTD & No/Links & No/Links & Yes \\
\hline BOTOX ${ }^{\circledR}$ Portal & http://www.botoxmedical.com & Allergan, Inc. & Cervical Dystonia only & Cervical Dystonia only & Yes \\
\hline
\end{tabular}

\section{Disclaimer}

The views expressed in the article are those of the authors and do not reflect the official policy of the Department of the Army, the Department of Defense or the U.S. Government.

\section{References}

Ade-Hall RA, Moore AP. 2000. Botulinum toxin type A in the treatment of lower limb spasticity in cerebral palsy. Cochrane Database of Systematic Reviews, (1):CD001408.

Albright AL, Gilmartin R, Swift D, et al. 2003. Long-term intrathecal baclofen therapy for severe spasticity of cerebral origin. J Neurosurg, 98:291-5.

Anderson TJ, Rivest J, Stell R, Steiger, et al. 1992. Botulinum toxin treatment of spasmodic torticollis. Journal Royal Society of Medicine, 85:524-9.

Aoki KR. 2005. Review of a proposed mechanism for the antinociceptive action of botulinum toxin type A. Neurotoxicology, 26:785-93.

Arezzo JC. 2002. Possible mechanisms for the effects of botulinum toxin on pain. Clin J Pain, 18:S125-9.

Babcock MS, Foster L, Pasquina P, et al. 2005. Treatment of pain attributed to plantar fasciitis with botulinum toxin a: a short-term, randomized, placebo-controlled, double-blind study. Am J Phys Med Rehabil, 84:649-54.

Baker R, Jasinski M, Maciag-Tymecka I, et al. 2002. Botulinum toxin treatment of spasticity in diplegic cerebral palsy: a randomized, double-blind, placebo-controlled, dose-ranging study. Dev Med Child Neurol, 44:666-75.

Barrientos N, Chana P. 1003. Botulinum toxin in prophylactic treatment of migraine headaches: a preliminary study. $J$ Headache Pain, 4:146-51.

Ben Simon GJ, McCann JD. 2005. Benign essential blepharospasm. Int Ophthalmol Clin, 45:49-75.

Benohanian A. 2007. Needle-free anaesthesia prior to botulinum toxin type A injection treatment of palmar and plantar hyperhidrosis. $\mathrm{Br} \mathrm{J}$ Dermatol, 156:593-6.

Benson J, Daugherty KK. 2007. Botulinum toxin A in the treatment of sialorrhea. Ann Pharmacother, 41:79-85.

Bhidayasiri R, Cardoso F, Truong DD. 2006. Botulinum toxin in blepharospasm and oromandibular dystonia: comparing different botulinum toxin preparations. Eur J Neurol, 13:21-9.

Bhidayasiri R, Truong DD. 2005. Expanding use of botulinum toxin. $J$ Neurol Sci, 235:1-9.

Blasi J, Chapman ER, Link E, et al. 1993. Botulinum neurotoxin A selectively cleaves synaptic protein SNAP-25. Nature, 365:160-3.

Blitzer A, Brin MF, Greene PE, et al. 1989. Botulinum toxin injection for the treatment of oromandibular dystonia. Ann Otol Rhinol Laryngol, 98:93-7.

Blitzer A. 2005. Botulinum toxin A and B: a comparative dosing study for spasmodic dysphonia. Otolaryngol Head Neck Surg, 133:836-8.

Borodic GE, Acquadro M, Johnson EA. 2001. Botulinum toxin therapy for pain and inflammatory disorders: mechanisms and therapeutic effects. Expert Opin Investig Drugs, 8:1531-44.
Borodic GE, Cozzolino D. 1989. Blepharospasm and its treatment, with emphasis on the use of botulinum toxin. Plast Reconstr Surg, 83:546-54.

Borodic GE, Ferrante R, Pearce LB, et al. 1994. Histologic assessment of dose-related diffusion and muscle fiber response after therapeutic botulinum A toxin injections. Mov Disord, 9:31-9.

BOTOX $^{\circledR}$ (botulinum toxin type A) package insert, 2004. Irvine, CA: Allergan, Inc.

BOTOX $^{\circledR}$ Portal Website [online]. Accessed August 10th, 2007. URL: http://www.botoxmedical.com

Brashear A, Bergan K, Wojcieszek J, et al. 2000. Patients' perception of stopping or continuing treatment of cervical dystonia with botulinum toxin type A. Mov Disord, 15:150-3.

Brashear A, Cullis P, Moiho E, et al. 1998. Cervical Dystonia Severity Scale (CDSS) reliability study. Mov Disord, 13:275.

Brashear A, Gordon MF, Elovic E, et al. 2002. Intramuscular injection of botulinum toxin for the treatment of wrist and finger spasticity after a stroke. N Engl J Med, 347:395-400.

Brashear A, Watts MW, Marchetti A, et al. 2000. Duration of effect of botulinum toxin type $\mathrm{A}$ in adult patients with cervical dystonia: a retrospective chart review. Clin Ther, 22:1516-24.

Brin M, Childers M, Esquenazi A et al. 1997. Dosing, administration, and a treatment algorithm for use of botulinum toxin A for adult-onsetspasticity. Muscle and Nerve, Suppl 6:S208-20.

Brin MF, Lyons KE, Doucette J, et al. 2001. A randomized, double masked, controlled trial of botulinum toxin type A in essential hand tremor. Neurology, 56:1523-8.

Byrnes ML, Thickbroom GW, Wilson SA, et al. 1998. The corticomotor representation of upper limb muscles in writer's cramp and changes following botulinum toxin injection. Brain, 121:977-88.

Cakmur R, Ozturk V, Uzunel F, et al. 2002. Comparison of preseptal and pretarsal injections of botulinum toxin in the treatment of blepharospasm and hemifacial spasm. $J$ Neurol, 249:64-8.

Campanati A, Lagalla G, Penna L, et al. 2004. Local neural block at the wrist for treatment of palmar hyperhidrosis with botulinum toxin: technical improvements. J Am Acad Dermatol, 51:345-8.

Cheng CM, Chen JS, Patel RP. 2006. Unlabeled uses of botulinum toxins: a review, part 1. Am J Health Syst Pharm, 63:145-52.

Childers MK, Brashear A, Jozefczyk P, et al. 2004. Dose-dependent response to intramuscular botulinum toxin type A for upper-limb spasticity in patients after a stroke. Arch Phys Med Rehabil, 85:1063-9.

Chung SS, Chang JH, Choi JY, et al. 2001. Microvascular decompression for hemifacial spasm: a long-term follow-up of 1,169 consecutive cases. Stereotact Funct Neurosurg, 77:190-3.

Comella CL, Buchman AS, Tanner CM, et al. 1992. Botulinum toxin injection for spasmodic torticollis: increased magnitude of benefit with electromyographic assistance. Neurology, 42:878-82.

Comella CL, Pullman SL. 2004. Botulinum toxins in neurological disease. Muscle Nerve, 29:628-44.

Comella CL, Thompson PD. 2006. Treatment of cervical dystonia with botulinum toxins. Eur J Neurol, 13:16-20.

Consky ES, Lang AE. 1994. Clinical assessments of patients with cervical dystonia. In Jankovic J, Hallett M eds. Therapy with botulinum toxin. New York, NY: Marcel Dekker, Inc, p 211-37. 
Cooper JG, Spilke CE, Denton M, et al. 2005. Clostridium botulinum: an increasing complication of heroin misuse. Eur J Emerg Med, 12:251-2.

Corry IS, Cosgrove AP, Duffy CM, et al. 1998. Botulinum toxin A compared with stretching casts in the treatment of spastic equinus: a randomised prospective trial. Journal of pediatric orthopaedics, 18:304-11.

Corry IS, Cosgrove AP, Walsh EG, et al. 1997. Botulinum toxin A in the hemiplegic upper limb: a double blind trial. Developmental Medicine and Child Neurology, 39:185-93.

Costa J, Espirito-Santo C, Borges A, et al. 2005a. Botulinum toxin type A therapy for blepharospasm. Cochrane Database Syst Rev, (1): CD004900.

Costa J, Espirito-Santo C, Borges A, et al. 2005b. Botulinum toxin type A therapy for cervical dystonia. Cochrane Database Syst Rev, (1): CD003633.

Costa J, Espirito-Santo C, Borges A, et al. 2005c. Botulinum toxin type A therapy for hemifacial spasm. Cochrane Database Syst Rev, (1): CD004899.

Craig AD. 2003. Pain mechanisms: labeled lines versus convergence in central processing. Annu Rev Neurosci, 26:1-30.

Critchfield J. 2002. Considering the immune response to botulinum toxin. Clin J Pain, 18:S133-41.

Cui M, Khanijou S, Rubino J, et al. 2004. Subcutaneous administration of botulinum toxin A reduces formalin-induced pain. Pain, 107:125-33.

Das CP, Dressler D, Hallett M. 2006. Botulinum toxin therapy of writer's cramp. Eur J Neurol, 13:55-9.

Davies J, Duffy D, Boyt N, et al. 2003. Botulinum toxin (BOTOX) reduces pain after hemorrhoidectomy: results of a double-blind, randomized study. Dis Colon Rectum, 46:1097-102.

de Paiva A, Meunier FA, Molgo J, et al. 1999. Functional repair of motor endplates after botulinum neurotoxin type A poisoning: biphasic switch of synaptic activity between nerve sprouts and their parent terminals. Proc Natl Acad Sci U S A, 96:3200-5.

Difazio M, Jabbari B. 2002. A focused review of the use of botulinum toxins for low back pain. Clin J Pain, 18:S155-62.

Djebbari R, du Montcel ST, Sangla S, et al. 2004. Factors predicting improvement in motor disability in writer's cramp treated with botulinum toxin. J Neurol Neurosurg Psychiatry, 75:1688-91.

Dolly JO, Aoki KR. 2006. The structure and mode of action of different botulinum toxins. Eur J Neurol, 13:1-9.

Dones I, Nazzi V, Broggi G. 2006. The guidelines for the diagnosis and treatment of spasticity. J Neurosurg Sci, 50:101-5.

Dong M, Yeh F, Tepp WH. 2006. SV2 is the protein receptor for botulinum neurotoxin A. Science, 312:592-6.

Dressler D. 2004. New formulation of BOTOX. Complete antibody-induced therapy failure in hemifacial spasm. J Neurol, 251:360.

Dressler D, Dirnberger G. 2000. Botulinum toxin therapy: risk factors for therapy failure. Mov Disord, 15:51.

Dressler D, Dirnberger G, Bhatia KP, et al. 2000. Botulinum toxin antibody testing: comparison between mouse protection assay and the mouse lethality assay. Mov Disord, 15:973-6.

Dressler D, Hallett M. 2006. Immunological aspects of BOTOX, Dysport and Myobloc/NeuroBloc. Eur J Neurol, 13:11-15.

Dressler D, Saberi FA. 2007. New formulation of BOTOX: complete antibody-induced treatment failure in cervical dystonia. J Neurol Neurosurg Psychiatry, 78:108-9.

Dressler D, Saberi FA, Barbosa ER. 2005. Botulinum toxin: mechanisms of action. Arq Neuropsiquiatr, 63:180-5.

Duchen LW, Strich SJ. 1968. The effects of botulinum toxin of the pattern of innervation of skeletal muscle in the mouse. Q J Exp Physiol, 53:84-9.

Duchen LW. 1971. An electron microscopic study of the changes induced by botulinum toxin in the motor end-plates of slow and fast skeletal muscle fibers of the mouse. J Neurol Sci, 14:47-60.

Dutton JJ, Fowler AM. 2007. Botulinum toxin in ophthalmology. Surv Ophthalmol, 52:13-31.

Dysport $^{\circledR}$ (botulinum toxin type A) package insert, 2005. Slough, UK: Ipsen, LTD.
Dysport $^{\mathbb{R}}$ Website [online]. Accessed August 10th, 2007. URL: http://www. dysport.co.nz/index.php

Eisenach JH, Atkinson JL, Fealey RD. 2005. Hyperhidrosis: evolving therapies for a well-established phenomenon. Mayo Clin Proc, 80:657-66.

Erbguth FJ. 1996. Historical note on the therapeutic use of botulinum toxin in neurological disorders. J Neurol Neurosurg Psychiatry, 60:151.

Evers S, Olesen J. 2006. Botulinum toxin in headache treatment: the end of the road? Cephalalgia, 26:769-71.

Evers S. 2006. Status on the use of botulinum toxin for headache disorders. Curr Opin Neurol, 19:310-15.

Fehlings D, Rang M, Glazier J, et al. 2000. An evaluation of botulinum-A toxin injections to improve upper extremity function in children with hemiplegic cerebral palsy. J Pediatr, 137:331-7.

Filippi GM, Errico P, Santarelli R. 1993. Botulinum A toxin effects on rat jaw muscle spindles. Acta Otolaryngol, 113:400-4.

Flett PJ, Stern LM, Waddy H, et al. 1999. Botulinum toxin A versus fixed cast stretching for dynamic calf tightness in cerebral palsy. Journal of Paediatrics and Child Health, 35:71-7.

Flynn TC. 2006. Update on botulinum toxin. Semin Cutan Med Surg, $25: 115-21$

Foster L, Clapp L, Erickson M, et al. 2001. Botulinum toxin A and chronic low back pain. Neurology, 56:1290-3.

Frei K, Truong DD, Dressler D. 2006. Botulinum toxin therapy of hemifacial spasm: comparing different therapeutic preparations. Eur J Neurol, 13:30-5.

Garza I, Swanson JW. 2006. Answers to frequently asked questions about migraine. Mayo Clin Proc, 81:1387-91.

Ghazizadeh S, Nikzad M. 2004. Botulinum toxin in the treatment of refractory vaginismus. Obstet Gynecol, 104:922-5.

Glogau RG. 2007. Topically applied botulinum toxin type A for the treatment of primary axillary hyperhidrosis: results of a randomized, blinded, vehicle-controlled study. Dermatol Surg, 33:S76-80.

Grant AC, Hermanowicz N. 2007. Reduction of EEG myogenic artifact with botulinum toxin during video-EEG monitoring. Epilepsia, 48:324-9.

Graven-Nielsen T, Mense S. 2001. The peripheral apparatus of muscle pain; evidence from animal and human studies. Clin J Pain, 17:2-10.

Greene P, Shale H, Fahn S. 1988. Analysis of open-label trials in torsion dystonia using high dosages of anticholinergics and other drugs. Mov Disord, 3:46-60.

Hanna PA. 1988. Mouse bioassay versus Western blot assay for botulinum toxin antibodies: correlation with clinical response. Neurology, 50:1624-9.

Hay JC. 2001. SNARE complex structure and function. Exp Cell Res, 271:10-21.

Hesse S, Reiter F, Konrad M, et al. 1998. Botulinum toxin type A and short-term electrical stimulation in the treatment of upper limb flexor spasticity after stroke: a randomized, double-blind, placebo-controlled trial. Clin Rehabil, 12:381-8.

Hockstein NG, Samadi DS, Gendron K, et al. 2004. Sialorrhea: a management challenge. Am Fam Physician, 69:2628-34.

Hsiung GY, Das SK, Ranawaya R, et al. 2002. Long-term efficacy of botulinum toxin A in treatment of various movement disorders over a 10-year period. Mov Disord, 17:1288-93.

Hyman N, Barnes M, Bhakta B, et al. 2000. Botulinum toxin (Dysport) treatment of hip adductor spasticity in multiple sclerosis: a prospective, randomised, double blind, placebo controlled, dose ranging study. $J$ Neurol Neurosurg Psychiatry, 68:707-12.

Jabbari B, Ney J, Sichani A, et al. 2006. Treatment of refractory, chronic low back pain with botulinum neurotoxin A: an open-label, pilot study. Pain Med, 7:260-4.

Jabbari B, Ney J. 2004. Treatment of low back pain with botulinum neurotoxins. Pain Pract, 4:S47-53.

Jankovic J, Schwartz K. 1995. Response and immunoresistance to botulinum toxin injections. Neurology, 45:1743-6.

Jankovic J, Vuong KD, Ahsan J. 2003. Comparison of efficacy and immunogenicity of original versus current botulinum toxin in cervical dystonia. Neurology, 60:1186-8. 
Jankovic J. 2004a. Botulinum toxin in clinical practice. J Neurol Neurosurg Psychiatry, 75:951-7.

Jankovic J. 2004b. Treatment of cervical dystonia with botulinum toxin. Mov Disord, 19:S109-15.

Jongerius PH, van den Hoogen FJ, van Limbeek J, et al. 2004. Effect of botulinum toxin in the treatment of drooling: a controlled clinical trial. Pediatrics, 114:620-7.

Jost WH, Kohl A. 2001. Botulinum toxin: evidence-based medicine criteria in blepharospasm and hemifacial spasm. J Neurol, 248:21-4.

Jost WH, Blumel J, Grafe S. 2007. Botulinum neurotoxin type A free of complexing proteins (XEOMIN ( (R))) in focal dystonia. Drugs, 67:669-83.

Karp BI. 2004. Botulinum toxin treatment of occupational and focal hand dystonia. Mov Disord, 19:S116-9.

Karp BI. 2004. Botulinum toxin treatment of occupational and focal hand dystonia. Mov Disord, 19:S116-9.

Keegan DJ, Geerling G, Lee JP, et al. 2002. Botulinum toxin treatment for hyperlacrimation secondary to aberrant regenerated seventh nerve palsy or salivary gland transplantation. British Journal of Opthalmology, 86:43-6.

Kemp LW, Reich SG. 2004. Hemifacial spasm. Curr Treat Options Neurol, 6:175-9.

Kennedy RH, Bartley GB, Flanagan JC, et al. 1989. Treatment of blepharospasm with botulinum toxin. Mayo Clin Proc, 64:1085-90.

Kern U, Martin C, Scheicher S, et al. 2003. Botulinum toxin type A influences stump pain after limb amputations. J Pain Symptom Manage, 26:1069-70.

Koman LA, Mooney JF, Smith BP, et al. 1994. Management of spasticity in cerebral palsy with botulinum-A toxin: report of a preliminary, randomized, double-blind trial. Journal of Pediatric Orthopaedics, 14:299-303.

Lagalla G, Millevolte M, Capecci M, et al. 2006. Botulinum toxin type A for drooling in Parkinson's disease: a double-blind, randomized, placebo-controlled study. Mov Disord, 21:704-7.

Lal D, Hotaling AJ. 2006. Drooling. Curr Opin Otolaryngol Head Neck Surg, 14:381-6.

Lance JW. 1980. The control of muscle tone, reflexes, and movement: Robert Wartenberg Lecture. Neurology, 30:1303-13.

Lang AM. 2003. Botulinum toxin type A therapy in chronic pain disorders. Arch Phys Med Rehabil, 84:S69-73.

Lew MF. 2002. Review of the FDA-approved uses of botulinum toxins, including data suggesting efficacy in pain reduction. Clin J Pain, 18:S142-6.

Lim EC, Seet RC, Chow A, et al. 2006. Topical botulinum toxin to treat hyperhidrosis? No sweat! Med Hypotheses, 67:27-32.

Lipp A, Trottenberg T, Schink T, et al. 2003. A randomized trial of botulinum toxin A for treatment of drooling. Neurology, 61:1279-81.

Lowe NJ, Glaser DA, Eadie N, et al. 2007. Botulinum toxin type A in the treatment of primary axillary hyperhidrosis: a 52-week multicenter double-blind, randomized, placebo-controlled study of efficacy and safety. J Am Acad Dermatol, 56:604-11.

Luvisetto S, Marinelli S, Cobianchi S. 2007. Anti-allodynic efficacy of botulinum neurotoxin A in a model of neuropathic pain. Neuroscience, 145:1-4.

Madalinski M, Chodorowski Z. 2006. Why the most potent toxin may heal anal fissure. Adv Ther, 23:627-34.

Mancini F, Sandrini G, Moglia A, et al. 2005. A randomised, double-blind, dose-ranging study to evaluate efficacy and safety of three doses of botulinum toxin type A (BOTOX) for the treatment of spastic foot. Neurol Sci, 26:26-31.

Mancini F, Zangaglia R, Cristina S, et al. 2003. Double-blind, placebocontrolled study to evaluate the efficacy and safety of botulinum toxin type A in the treatment of drooling in parkinsonism. Mov Disord, 18:685-8.

Mannion RJ, Woolf C. 2000. Pain mechanisms and management: a central perspective. Clin J Pain, 16:S144-56.

Manno I, Antonucci F, Caleo M, et al. 2007. BoNT/E prevents seizure-induced activation of caspase 3 in the rat hippocampus. Neuroreport, 18:373-6.
Markey AC. 2004. Dysport. Dermatol Clin, 22:213-19.

Maselli RA, Burnett ME, Tonsgard JH. 1992. In vitro microelectrode study of neuromuscular transmission in a case of botulism. Muscle Nerve, 15:273-6.

Mauriello JA. 2002. Botulinum toxin type A with blepharospasm and hemifacial spasm. In Brin MF, Jancovic J, Hallett M eds. Scientific and therapeutic aspects of botulinum toxin. Philadelphia: Lippincott, Williams, and Wilkins. p 197-205.

Mauskop A. 2007. Botulinum toxin in headache treatment: the end of the road? Cephalalgia, 27:468.

Mayer N, Esquenazi A, Childers M. 1997. Common patterns of clinical motor dysfunction. Muscle and Nerve, Suppl 6:S21-35.

Meyer KF. 1956. The status of botulism as a wokd health problem. Bull WHO, 15:281-98.

Molloy FM, Shill HA, Kaelin-Lang A, et al. 2002. Accuracy of muscle localization without EMG: implications for treatment of limb dystonia. Neurology, 58:805-7.

Montecucco C, Schiavo G, Rosetto O. 1996. The mechanism of action of tetanus and botulinum neurotoxins. Arch Toxicol, 18:342-54.

Naumann M, Jankovic J. 2004. Safety of botulinum toxin type A: a systematic review and meta-analysis. Curr Med Res Opin, 20:981-90.

Naumann M, Jost W. 2004. Botulinum toxin treatment of secretory disorders. Mov Disord, 19:S137-41.

Neurotoxin Institute Website [online] Accessed August 10, 2007. URL: http://www.neurotoxininstitute.org/

Ney JP, Difazio M, Sichani A, et al. 2006. Treatment of chronic low back pain with successive injections of botulinum toxin a over 6 months: a prospective trial of 60 patients. Clin J Pain, 22:363-9.

Nolte D, Gollmitzer I, Loeffelbein DJ, et al. 2004. [Botulinum toxin for treatment of gustatory sweating. A prospective randomized study]. Mund Kiefer Gesichtschir, 8:369-75.

Odergren T, Hjaltason H, Kaakkola S, et al. 1998. A double blind, randomised, parallel group study to investigate the dose equivalence of Dysport and BOTOX in the treatment of cervical dystonia. $J$ Neurol Neurosurg Psychiatry, 64:6-12.

Osborne SL, Latham CF, Wen PJ, et al. 2007. The Janus faces of botulinum neurotoxin: sensational medicine and deadly biological weapon. $J$ Neurosci Res, 85:1149-58.

Patel AK, Chapple CR. 2006. Botulinum toxin injection therapy in the management of lower urinary tract dysfunction. Int J Clin Pract Suppl, 151:1-7.

Pathak MS, Nguyen HT, Graham HK, et al. 2006. Management of spasticity in adults: practical application of botulinum toxin. Eur J Neurol, 13:42-50.

Porta M, Maggioni G, Ottaviani F, et al. 2004. Treatment of phonic tics in patients with Tourette's syndrome using botulinum toxin type A. Neurol Sci, 24:420-3.

Potulska A, Friedman A. 2005. Controlling sialorrhoea: a review of available treatment options. Expert Opin Pharmacother, 6:1551-4.

Reich SG, Grill SE. 2001. Gustatory sweating: Frey syndrome. Neurology, 65:E24.

Rieder CR, Schestatsky P, Socal MP, et al. 2007. A double-blind, randomized, crossover study of prosigne versus BOTOX in patients with blepharospasm and hemifacial spasm. Clin Neuropharmacol, 30:39-42.

Roberts WJ. 1986. A hypothesis on the physiological basis for causalgia and related pains. Pain, 24:297-311.

Ron Y, Avni Y, Lukovetski A, et al. 2001. Botulinum toxin type-A in therapy of patients with anismus. Dis Colon Rectum, 44:1821-6.

Sakaguchi G. 1983. Clostridium Botulinum toxins. Pharmacol Ther, 19:165-94.

Rosales RL, Bigalke H, Dressler D. 2006. Pharmacology of botulinum toxin: differences between type A preparations. Eur J Neurol, 13 Suppl 1:2-10.

Rotenberg JS, Canard K, Difazio M. 2006. Successful treatment of recalcitrant restless legs syndrome with botulinum toxin type-A. J Clin Sleep Med, 2:275-8. 
Russo RN, Crotty M, Miller MD, et al. 2007. Upper-limb botulinum toxin A injection and occupational therapy in children with hemiplegic cerebral palsy identified from a population register: a single-blind, randomized, controlled trial. Pediatrics, 119:e1149-58.

Sampaio C, Ferreira JJ, Simoes F, et al. 1997. DYSBOT: a single-blind, randomized parallel study to determine whether any differences can be detected in the efficacy and tolerability of two formulations of botulinum toxin type A - Dysport and BOTOX - assuming a ratio of 4:1. Mov Disord, 12:1013-8.

Schantz EJ, Johnson EA. 1997. Botulinum toxin: the story of its development for the treatment of human disease. Perspect Biol Med, 40:317-27.

Schneider SA, Edwards MJ, Grill SE, et al. 2006. Adult-onset primary lower limb dystonia. Mov Disord, 21:767-71.

Schomburg ED, Stephens H, Klaus-Dieter K. 1999. Contribution of group III and IV afferents to multisensorial spinal motor control in cats. Neurosci Res, 33:95-206.

Schwartz M, Freund B. 2002. Treatment of temporomandibular disorders with botulinum toxin. Clin J Pain, 18:S198-203.

Scott AB, Kennedy RA, Stubbs HA. 1985. Botulinum A toxin injection as a treatment for blepharospasm. Arch Ophthalmol, 103:347-50.

Scott AB, Rosenbaum A, Collins CC. 1973. Pharmacologic weakening of the extraocular muscles. Invest Opthamol, 12:924-7.

Scott AB, Suzuki D. 1988. Systemic toxicity of botulinum toxin by intramuscular injection in the monkey. Mov Disord, 3:333-5.

Setler PE. 2002. Therapeutic use of botulinum toxins: background and history. Clin J Pain, 18:S119-24.

Shapiro RL, Hatheway C, Swerdlow DL. 1998. Botulism in the United States: a clinical and epidemiologic review. Ann Intern Med, 129:221-8.

Sheean GL. 2001. Botulinum treatment of spasticity: why is it so difficult to show a functional benefit? Curr Opin Neurol, 14:771-6.

Silberstein S, Mathew N, Saper J, et al. 2000. Botulinum toxin type A as a migraine preventive treatment. For the BOTOX Migraine Clinical Research Group. Headache, 40:445-50.

Silberstein S. 2004. Botulinum neurotoxins: origins and basic mechanisms of action. Pain Practice, 4:S19-26.

Simpson DM, Alexander DN, O'Brien CF, et al. 1996. Botulinum toxin type $\mathrm{A}$ in the treatment of upper extremity spasticity: a randomized, double-blind, placebo-controlled trial. Neurology, 46:1306-10.

Simpson LL. 2000. Identification of the characteristics that underlie botulinum toxin potency: implications for designing novel drugs. Biochemie, 82:942-53.

Simpson LL. 1980. Kinetic studies on the interaction between botulinum toxin type A and the cholinergic neuromuscular junction. J Pharm Exp Ther, 212:16-21.

Singer C, Papapetropoulos S. 2006. Adult-onset primary focal foot dystonia. Parkinsonism Relat Disord, 12:57-60.

Speelman JD, Brans JW. 1995. Cervical dystonia and botulinum treatment: is electromyographic guidance necessary? Mov Disord, 10:802.

Talarico-Filho S, Mendonca DO, Nascimento M, et al. 2007. A double-blind, randomized, comparative study of two type A botulinum toxins in the treatment of primary axillary hyperhidrosis. Dermatol Surg, 33:S44-50.

Tan EK, Jankovic J. 1999. Botulinum toxin A in patients with oromandibular dystonia: long-term follow-up. Neurology, 53:2102-7.

Tan EK. 2006. Botulinum toxin treatment of sialorrhea: comparing different therapeutic preparations. Eur J Neurol, 13:60-4.

Tan NC, Chan LL, Tan EK. 2002. Hemifacial spasm and involuntary facial movements. QJM, 95:493-500.
Tang X, Wan X. 2000. Comparison of BOTOX with a Chinese type A botulinum toxin. Chin J Med, 115:794-8.

Tarsy D, Simon DK. 2006. Dystonia. N Engl J Med, 355:818-29.

Tolosa E, Kulisevsky J, Fahn S. 1988. Meige syndrome: primary and secondary forms. Adv Neurol, 50:509-15.

Truong D. 2005. Efficacy and safety of botulinum toxin type A toxin complex (Dysport) for the treatment of benign essential blepharospasm. Parkinsonism and Related Disorders, 11:68.

Tsai CP, Liu CY, Lin KP, et al. 2006. Efficacy of botulinum toxin type a in the relief of Carpal tunnel syndrome: a preliminary experience. Clin Drug Investig, 26:511-5.

Tsui JK, Bhatt M, Calne S, et al. 1993. Botulinum toxin in the treatment of writer's cramp: a double-blind study. Neurology, 43:183-5.

Tsui JK, Eisen A, Mak E, et al. 1985. A pilot study on the use of botulinum toxin in spasmodic torticollis. Can J Neurol Sci, 12:314-6.

Tsui JK, Eisen A, Stoessl AJ. 1986. Double-blind study of botulinum toxin in spasmodic torticollis. Lancet, 2:245-7.

Unal M, Sevim S, Dogu S, et al. 2003. Effect of botulinum toxin A on nasal symptoms in allergic rhinitis: a double blind, placebo controlled trial. Acta Otolaryngologica, 123:1060-3.

Van den Bergh P, Francart J, Mourin S, et al. 1995. Five-year experience in the treatment of focal movement disorders with low-dose Dysport botulinum toxin. Muscle Nerve, 18:720-9.

Van Ermengem E. 1979. Classics in infectious diseases. A new anaerobic bacillus and its relation to botulism. Rev Infect Dis, 4:701-19.

Van Zandijcke M, Marchau MM. 1990. Treatment of bruxism with botulinum toxin injections. J Neurol Neurosurg Psychiatry, 53:530.

Verrotti A, Greco R, Spalice A. 2006. Pharmacotherapy of spasticity in children with cerebral palsy. Pediatr Neurol, 34:1-6.

Wallen M, O'Flaherty SJ, Waugh MC. 2007. Functional outcomes of intramuscular botulinum toxin type a and occupational therapy in the upper limbs of children with cerebral palsy: a randomized controlled trial. Arch Phys Med Rehabil, 88:1-10.

Ward AB, Molenaers G, Colosimo C, et al. 2006. Clinical value of botulinum toxin in neurological indications. Eur J Neurol, 13:20-6.

Wasiak J, Hoare B, Wallen M. 2004. Botulinum toxin A as an adjunct to treatment in the management of the upper limb in children with spastic cerebral palsy. Cochrane Database of Systematic Reviews, (4):CD003469.

WEMOVE ${ }^{\mathrm{TM}}$ Website [online] Accessed April 10th, 2007. URL: http://www. mdvu.org/library/dosingtables/btxa_adg_dys.html

Wissel J, Kanovsky P, Ruzicka E, et al. 2001. Efficacy and safety of a standardised 500 unit dose of Dysport (clostridium botulinum toxin type A haemaglutinin complex) in a heterogeneous cervical dystonia population: results of a prospective, multicentre, randomised,double-blind, placebo-controlled, parallel group study. J Neurol, 248:1073-8.

Wohlfarth K, Muller C, Sassin I, et al. 2007. Neurophysiological doubleblind trial of a botulinum neurotoxin type A free of complexing proteins. Clin Neuropharmacol, 30:86-94.

Xeomin $^{\circledR}$ Website [online]. Accessed August 10th, 2007. URL: http:// www.xeomin.com

Yang TF, Fu CP, Kao NT, et al. 2003. Effect of botulinum toxin type A on cerebral palsy with upper limb spasticity. Am J Phys Med Rehabil, 82:284-9.

Yoshimura DM, Aminoff MJ, Tami TA, et al. 1992. Treatment of hemifacial spasm with botulinum toxin. Muscle Nerve, 15:1045-9. 